\title{
Factors associated with quality of sleep of nurses at Rafsanjan University of Medical Sciences, Iran, in 2013
}

\author{
Kazemi M, $\mathrm{PhD}^{1}$, Hosieni F, MSc ${ }^{2 *}$, Rezaeian M, $\mathrm{PhD}^{3}$, Fasihihharandi T, $\mathrm{PhD}^{4}$, Akbary A, MSc ${ }^{5}$ \\ 1-Assistant prof., of Nursing, Dept. of Medical Surgrical Nursing, Faculty of Nursing \& Midwifery, Rafsanjan University \\ of Medical Sciences, Rafsanjan, Iran. 2-MSc in Community Health Nurse, Geriatric Care Research Center, Rafsanjan \\ University of Medical Sciences, Rafsanjan, Iran. 3-Professor, Dept. of Epidemiology and Biostatistics, Occupational \\ Environmental Research Center, Medical School, Rafsanjan University of Medical Sciences, Rafsanjan, Iran. 4-Assistant \\ prof., Social Determinants of Health Research Center, Alborz University of Medical Sciences, Karaj, Iran. 5-Instructor, \\ Dept. of Medical Surgrical Nursing, Faculty of Nursing \& Midwifery, Rafsanjan University of Medical Sciences, Rafsanjan, \\ Iran.
}

\begin{abstract}
Received: December 2015, Accepted: April 2016

Background: Sleep and rest are basic physiological human needs. Nurses work irregularly in morning, afternoon, and evening shifts; therefore, they are at greater risk of sleep problems than others. The aim of this study was to identify the factors related to sleep quality of nurses at Rafsanjan University of Medical Sciences, Iran.

Materials and Methods: This cross-sectional study was conducted in 2013. The study subjects consisted of 366 nurses who were randomly selected from among nurses working at the medical university. Data collection tools included the occupational demographic questionnaire and Pittsburgh Sleep Quality Index (PSQI). Data analysis was performed using chi-square test and logistic regression model in SPSS software.

Results: It was found that $273(74.7 \%)$ of the nurses had poor sleep quality. The overall mean score of nurses was $7.35 \pm 2.86$. The logistic regression model showed a statistically significant relationship between poor sleep quality and variables of age $(\mathrm{P}=0.030)(95 \% \mathrm{CI}: 1.09-1.010)(\mathrm{OR}=1.50)$, gender $(\mathrm{P}=0.001)(95 \% \mathrm{CI}: 0.23-0.70)(\mathrm{OR}=0.40)$, number of night shifts $(\mathrm{P}=0.003),(95 \% \mathrm{CI}: 1.138$ 1.11) $(\mathrm{OR}=1.20)$, and having children of less than one year of age $(\mathrm{P}=0.019)(95 \% \mathrm{CI}: 3.8-1.12)$ $(\mathrm{OR}=2.10)$. The chi-square test showed a significant relationship between poor sleep quality and the type of working shift $(\mathrm{P}=0.001)$. About one-third of the nurses in this study used medicine for sleeping and had difficulty in falling asleep.

Conclusions: The results indicated that the sleep quality of the majority of the nurses was poor. It is suggested that a certain guideline be developed for planning nurses' schedules using the results of this study and other studies in this area.
\end{abstract}

Keywords: Sleep, Nurses, Nursing.

\section{Introduction}

Sleep and rest are basic human needs. They are placed on Maslow's hierarchy of needs as physiological needs. They provide opportunity for re-energizing and relief from stress for the human body (1). When the sleep-wake cycle is disrupted, the other physiological functions of the body will also undergo change (2). An adult requires 6-8 hours of sleep during one day. Sleep is essential for tissue repair and growth (3). Insomnia results in mental or physical symptoms. The severity of these symptoms depends on the duration of sleep deprivation (3). Environmental factors such as occupational and physiological changes could change the quality and quantity of sleep and disrupt its natural pattern (4). Irregular sleeping patterns, particularly in occupations which have different working shifts are more common (5).

\footnotetext{
Corresponding author: Fatemeh Hosieni, Geriatric Care Research Center, Rafsanjan University of Medical Sciences, Rafsanjan, Iran.

Email: hossini1389@yahoo.com
} 
Nurses constitute the largest group of professionals in the healthcare system (1). Due to the nature of their work, nurses operate irregularly in morning, afternoon, and night shifts, and thus, are at risk of complications of insomnia (1) much of which are not controllable (6). Insomnia has unpleasant impacts on the natural life of nurses and their families (1). Every year, a large number of nurses experience medical errors due to excessive sleepiness (7) which result in serious patient injury (8-10). Many studies have shown the association between sleep disturbance and nursing errors $(11,12)$.

Allocation of different shifts during the day to nurses is unavoidable since patients admitted to hospitals require 24hour care services; therefore, the factors of shifts and night work cannot be eliminated (13). The most effective treatment for sleep deprivation among nurses is to reduce or correct the factors that disrupt their sleep-wake pattern (14). There are many occupational and individual factors that influence the sleep quality of nurses.

Most of the studies which have been conducted on the nurses' sleep were related to the circadian rhythm (15), childcare, home responsibility and leisure time (16), relationship between sleep quality and general health (17), quality of life (QOL) (18), nursing errors (19), traffic accidents (20), hormonal changes (21), and different diseases (22). However, few studies have assessed the underlying factors that affect the sleep quality of nurses, especially the cultural differences that should be noted in this regard (16).

The researcher, based on her clinical experience, conducted this study with the aim to identify variables associated with nurses' sleep quality, so that the results could be used by the authorities in planning to reduce the underlying sleep-related factors among nurses.

\section{Material and Methods}

This was a cross-sectional study. The study population included 700 nurses and paramedics who worked at the medical centers
(Ali-ibn Abi Talib, Niknafs Maternity, Moradi hospitals, Annar and Shahre Babak) affiliated to Rafsanjan University of Medical Sciences, Iran, and had at least 6 months of work experience. From among these nurses, 400 were randomly selected (based on the even numbers in the employees' monthly schedule). Pregnancy, addiction, recent acute problems, diseases that affect sleep quality, and the loss of loved ones in the last 6 months were among the exclusion criteria. Ethical principles, such as obtaining an informed consent from the participants, explaining the research and its objectives to the nurses, preserving confidentiality in the dissemination of information, and providing participants the freedom to withdraw from the study, were observed. Data were collected using a questionnaire through self-report by the nurses. Finally, 366 questionnaires that were fully completed were analyzed.

Data collection tools consisted of an occupational and demographic questionnaire and the Pittsburgh Sleep Quality Index (PSQI). The occupational and demographic questionnaire included questions regarding age, gender, child of less than one year of age, type of ward, education, type of working shifts, sleep quantity, and the number of night shifts.

To evaluate sleep quality of the nurses, the PSQI was used. This questionnaire obtains and assesses the nurses' perspective toward the quality of their sleep during the previous month through self-report. The validity and reliability of the PSQI were $96.6 \%$ and $86.5 \%$, respectively (23). This questionnaire has been used in many studies and has shown high reliability and validity $(4,13)$. This questionnaire includes the 7 scales of general description of the quality of sleep, delays in falling asleep, the duration of high quality sleep, sleep efficiency (the ratio of sleep duration to total elapsed time in bed), sleep disorders (defined as sleep fragmentation), the amount of sleeping drug consumed, morning performance (problems experienced by the individual during the day resulting from poor 
sleep). The score of each scale of the questionnaire ranged between 0 and 3 . Scores $0,1,2$, and 3 in each scale represented normal, and mild, moderate, and severe problems, respectively. The total of the scores of the 7 scales formed the total score which was in the range of 0 to 21 . Scores of 5 and higher represent poor quality sleep (24).

Data were analyzed using logistic regression and chi-square test in SPSS software (version 18, SPSS Inc., Chicago, IL, USA).

Moreover, for the appropriate fitting of the logistic regression model, the HosmerLemeshow (HL) test and the receiver operating characteristic (ROC) curve were used.

\section{Results}

The subjects' mean and standard deviation of age was $32.76 \pm 8.03$ years and the highest percentage of subjects was in the age group of less than 30 years. The minimum age of the participants was 18 years and the maximum age was 57 years. The nurses in this study had a minimum of 1 year and a maximum of 30 years of work experience. Mean and standard deviation of the number of night shifts was $6.43 \pm 2.91$ nights. In this study, 262 of the nurses (68.20\%) were women, and the majority of them were married $(71.01 \%)$.
Moreover, 241 nurses (62.1\%) had a bachelor's degree and 300 nurses (81.96\%) had rotating working shifts.

Chi-square test showed that satisfactory and bad quality sleep (score of 5 or more meant bad sleep quality, and score of less than 5 meant satisfactory sleep quality) had a significant relationship with the type of working shifts $(P=0.001)$. Nurses who had rotating working shifts had the worst quality of sleep. There was no significant relationship between the type of ward $(P=0.202)$, sleep quantity $(\mathrm{P}=0.080)$ during day and night, and education level $(\mathrm{P}=0.060)$ (Table 1). In addition, 93 (25.3\%) of the subjects had good sleep quality, and 273 cases $(74.7 \%)$ had poor sleep quality. The overall mean score for sleeping was $7.35 \pm 2.869$.

Using logistic regression model, the binary variable of sleep quality (satisfactory and bad) was demonstrated. For variables that were statistically significant, the P-value is marked with an asterisk. In the evaluation of the appropriate fitting of the model using HL test $\mathrm{P}$ equaled 0.89. This showed that the regression model was appropriate for sleep quality. Furthermore, the area under the ROC curve was 70.0, which indicated its suitability for sleep quality.

Table 1: Nursing profession characteristics and satisfactory and bad quality of sleep

\begin{tabular}{|c|c|c|c|c|c|c|c|}
\hline \multirow{2}{*}{\multicolumn{2}{|c|}{ Quality of sleep }} & \multicolumn{2}{|c|}{ Good sleep quality } & \multicolumn{2}{|c|}{ Poor sleep quality } & \multirow[t]{2}{*}{ Total } & \multirow{2}{*}{ Statistical tests } \\
\hline & & Frequency & $\%$ & Frequency & $\%$ & & \\
\hline \multirow{4}{*}{$\begin{array}{l}\text { Education } \\
\text { level }\end{array}$} & Diploma & 10 & 10.9 & 45 & 16.4 & 55 & \multirow{4}{*}{$\begin{array}{c}P=0.060 \\
\text { Chi_squre }=7.42 \\
\text { Df }=3\end{array}$} \\
\hline & Advanced diploma & 24 & 26.1 & 41 & 15 & 65 & \\
\hline & Bachelor & 56 & 60.9 & 175 & 63.9 & 231 & \\
\hline & Master degree & 2 & 2.2 & 13 & 4.7 & 15 & \\
\hline \multirow{5}{*}{$\begin{array}{c}\text { The } \\
\text { hospital } \\
\text { wards }\end{array}$} & Emergency & 35 & 43.75 & 25 & 41.66 & 60 & \multirow{5}{*}{$\begin{array}{c}\mathrm{P}=0.072 \\
\text { Chi-square }=7.42 \\
\text { Df }=3\end{array}$} \\
\hline & Pediatrics & 17 & 60.29 & 10 & 37.03 & 27 & \\
\hline & $\begin{array}{c}\text { Surgery and } \\
\text { internal }\end{array}$ & 30 & 60.00 & 20 & 40.00 & 50 & \\
\hline & Intensive care & 60 & 80.00 & 15 & 20.00 & 75 & \\
\hline & Another & 99 & 64.28 & 55 & 35.71 & 154 & \\
\hline \multirow{3}{*}{$\begin{array}{l}\text { Quantity } \\
\text { of sleep }\end{array}$} & $>5$ & 40 & 60.60 & 26 & 39.39 & 66 & \multirow{3}{*}{$\begin{array}{c}\mathrm{P}=0.08 \\
\text { Chi-square }=0.75 \\
\text { Df }=3.108\end{array}$} \\
\hline & 6-9 & 170 & 77.27 & 50 & 22.72 & 220 & \\
\hline & $9<$ & 48 & 60.00 & 32 & 40.00 & 80 & \\
\hline \multirow{3}{*}{$\begin{array}{l}\text { Shift } \\
\text { types }\end{array}$} & Rotating shifts & 225 & 75.00 & 75 & 25.00 & 300 & \multirow{3}{*}{$\begin{array}{c}\mathrm{P}=0.001 \\
\mathrm{Df}=3.108 \\
\text { Chi-square }=0.75\end{array}$} \\
\hline & $\begin{array}{l}\text { Morning or evening } \\
\text { doesn't have night }\end{array}$ & 30 & 68.18 & 14 & 31.81 & 44 & \\
\hline & $\begin{array}{c}\text { Fixed } \\
\text { morning } \\
\text { and evening }\end{array}$ & 13 & 59.9 & 9 & 40.90 & 22 & \\
\hline
\end{tabular}


Table 2: Logistic regression model, quality of sleep and its relationship with demographic characteristics, and confidence interval odds ratio for each of the variables

\begin{tabular}{lcccc}
\hline \multicolumn{1}{c}{ Variables } & Odds ratio & Lower CI & Upper CI & P-valve \\
\hline Gender & 0.40 & 0.23 & 0.70 & $0.001^{*}$ \\
\hline Age & 1.05 & 1.010 & 1.09 & $0.031^{*}$ \\
\hline Number of night shifts & 1.20 & 1.11 & 1.38 & $0.003^{*}$ \\
\hline $\begin{array}{l}\text { Having children of less than } \\
\text { one year of age: yes }\end{array}$ & 2.10 & 1.12 & 3.8 & $0.019^{*}$ \\
\hline
\end{tabular}

In the logistic regression model, the relationship between sleep quality and variables of age, gender, marital status, number of night shifts, and having children of less than one year of age were investigated. Variables such as quantity of sleep, type of ward, level of education, type of working shift, the number of children, marital status, and work experience, which were not significant, were not included in the sleep quality model. Another reason for the exclusion of these variables from the model was that age was highly correlated with work experience (correlation $=0.88$ ). Therefore, only age was included to avoid the issue of collinearity. This matter was also true for the number of night shifts and the type of working shifts. Thus, only the number of night shifts was included in the model. When only "having a child of less than one year of age" was included in the model, the P-value was better than in the case of "having a child of less than two years of age" and "having a child of less than three years of age". Therefore, only the variable of "having a child of less than one year of age" was included in the model.

Regarding marital status, the $\mathrm{P}$ value was far from the significant level, and it was highly correlated with "having a child of less than one year of age" (correlation $=0.88$ ). Therefore, it was not included in the logistic regression model to avoid collinearity. Akaike information criterion (AIC) values of "having children of less than one year of age", "having children of less than two years of age", "having children of less than three years of age" were, respectively, 44.34, 34.350, and 56.351, and the smallest AIC value was related to "having children of less than one year of age". The variables of "having children of less than one year of age", "having children of less than two years of age", and "having children of less than three years of age" had P-values of $0.10,0.05$, and 0.01 , respectively. Having children of less than one year of age was statistically significant in the model.

Table 3: Mean and standard deviation of each of the dimensions of sleep quality, the number of nurses who had sleep problems

\begin{tabular}{|c|c|c|c|c|}
\hline \multirow{2}{*}{ Dimensions of quality of sleep } & \multicolumn{3}{|c|}{ Nurses with problems } & \multirow{2}{*}{ Mean \pm SD } \\
\hline & Male & Female & Total & \\
\hline Medication use for sleeping & $83(\% 66.92)$ & $41(\% 33.06)$ & $124(\% 33.87)$ & $1.01 \pm 0.67$ \\
\hline Sleeping disorder & $50(\% 45.45)$ & $60(\% 54.54)$ & $110(\% 30.23)$ & $1.27 \pm 0.54$ \\
\hline Habits & $45(\% 49.45)$ & $49(\% 50.54)$ & $91(\% 25.50)$ & $0.59 \pm 0.50$ \\
\hline Duration of a high quality sleep & $50(\% 45.04)$ & $61(\% 54.95)$ & $111(\% 30.30)$ & $1.10 \pm 0.25$ \\
\hline Delay in sleeping & $75(\% 53.57)$ & $65(\% 46.42)$ & $140(\% 38.01)$ & $1.20 \pm 0.50$ \\
\hline Mental quality of sleeping & $42(\% 51.21)$ & $40(\% 48.78)$ & $82(\% 22.20)$ & $1.25 \pm 0.25$ \\
\hline Daily disorders caused by sleeping & $40(\% 49.38)$ & $41(\% 50.61)$ & $81(\% 22.15)$ & $0.93 \pm 0.15$ \\
\hline \multirow[t]{2}{*}{ Total score } & $6.32 \pm 3.60$ & $7.58 \pm 3.59$ & $7.29 \pm 3.66$ & $7.35 \pm 2.86$ \\
\hline & \multicolumn{2}{|l|}{$\mathrm{P}=0.0002^{*}$} & $\mathrm{df}=3.104$ & \\
\hline
\end{tabular}


Variables, such as age, gender, number of night shifts, and having children of less than one year of age, were significant in the model in terms of the quality of sleep. In this model, men had better sleep quality than women. Individuals who were older, had more night shifts, or had children of less than one year of age had less chance of having a satisfactory sleep quality. For example, the chance of having bad quality sleep with having children of less than one year of age was 2.1 times higher (Table 2).

Among the participants, $38.1 \%$ indicated that they fall asleep 30 minutes after going to bed. Mean morning waking hour was estimated at 6 in the morning. Moreover, $30.30 \%$ of the participants stated that they wake up at least one hour before the considered time. Based on the results, $33.80 \%$ of the participants had to use medication to sleep (Table 3).

\section{Discussion}

In this study, $25.3 \%$ of the nurses had satisfactory sleep quality, and $74.7 \%$ had poor sleep quality. In the study by Bagheri et al., $77.7 \%$ of the participants had poor sleep quality and $22.3 \%$ had satisfactory sleep quality (25). The mean score of sleep of the nurses was $7.29 \pm 3.66$ which was consistent with the study by Akbari et al. (4). Many studies reported the mean score of sleep quality of nurses as greater than $5(2,15,26)$ which was higher than the quality of sleep score of ordinary individuals $(4,26)$. Through the comparison of the results of these studies it can be concluded that the quality of sleep of nurses is poor.

In this study, nurses who did not have night shifts had better quality of sleep compared to the others. This result was consistent with the results of the studies by Lin et al. (27) and Ghaljayi et al. (13). There was also a significant relationship between quality of sleep and the number of night shifts; as the number of night shifts increased, the quality of sleep of nurses decreased. In the study by Rahimpour et al., with increase in night shifts, the quality of sleep of nurses decreased (28). Night shifts are an inevitable part of nursing, but the complications can be reduced by reducing the number of night shifts per month. There was a significant difference between nurses who worked in different shifts in terms of quality of sleep. Nurses who had rotating shifts had the worst quality of sleep. Salehi et al. observed a statistically significant difference between the quality of sleep of nurses with fixed working shifts and nurses with rotating working shifts (10). In other studies, nurses who worked on night shifts required more rest than nurses who had fixed working shifts and did not have night shifts $(29,30)$. The results of this study and other studies showed the effects of working shifts on the quality of sleep and they indicated the need for more attention to reducing the harmful effects of working shifts. Therefore, designing detailed studies in this field is recommended.

The possibility of poor sleep with a child of less than one year of age was twice that without a child of less than one year of age (2.1 times). Taking care of a child requires much time and energy, especially during infancy because the child wakes up during the night. This matter affects the quality of sleep of nurses especially when they have night shifts. It should be noted that this issue was not mentioned in other studies.

Based on the results of this study, male nurses had better sleep quality than female nurses. These results were consistent with the study by Karagozoglu and Bingöl, in which the mean score of sleep quality was higher for women than men (31). This result was justified by the great responsibility of women in the family. Research showed that most nurses, especially women, due to their responsibilities in the family (taking care of children and the elderly), sleep less than 6 hours in 24 hours (32). Generally, home is a place for relaxation and stress relief from the outside world. This is true for most men, children, and adults; however, for most women, as long as they are awake (sometimes even in their sleep), home is a workplace and this issue indirectly affects 
the care provided for the patient. This condition of women should be considered and compulsory overtime and shifts for women should be avoided in order to provide safe patient care.

In this study, with increase in age the mean score of quality of sleep also increased. In other words, the quality of sleep of nurses decreased with aging. There was a higher rate of sleep disorders in the elderly. In other studies, older people were less able to adapt to night shifts $(26,33,34)$. Therefore, early retirement is recommended for nurses, so that younger people who have more ability to adapt to circadian rhythm disorders can be employed.

The results showed that one-third of the nurses had disrupted sleep onset and short duration nighttime sleep. They also woke up earlier than desired. One-third of the participants used medication for sleeping. Kageyama et al. studied 785 female nurses working in hospitals and found that the prevalence of insomnia among nurses was $2.29 \%$, and $23 \%$ of nurses used sleeping pills to treat their sleep disorders (35). In the study by Bagheri et al., in 50\% of nurses, the duration until they slept, the mean waking hour, and use of medication was consistent with this study (25). In justifying these results, it should be stated that most nurses have the responsibility of caring for their families; therefore, they have short periods of rest, and their sleep quality is poor due to light and sounds (13). They work during sleeping hours and try to sleep during the active hours of the day which results in insufficient sleep and fatigue among these individuals (36). Small gaps between shifts were also effective. Therefore, many of nurses turn to using sleeping medications. This is a concern for nursing administrators.

\section{Conclusion}

The results showed that most nurses had poor quality of sleep. The majority of nurses have problems falling sleep and they use medication for this issue. There was a significant relationship between quality of sleep and occupational and individual characteristics such as age, gender, type of shifts, number of night shifts, and having children of less than one year of age. Therefore, nurses require professional help and support and the officials should find the right solution for their sleep disorders. Developing a certain guideline for planning nurses' schedules using the results of this study and other studies in this area is suggested.

\section{Acknowledgments}

This article was the result of a final master's thesis. Our sincere appreciation goes to the nurses at Ali-ibn Abi Talib, Niknafs Maternity, Moradi hospitals, Annar and Shahre Babak, Rafsanjan, Iran, for their assistance in conducting this study.

Conflict of interest: None declared.

\section{References}

1. Bahri N, Shamshri M, Moshki M, Mogharab M. The survey of sleep quality and its relationship to mental health of hospital nurses. Iran Occupational Health 2014; 11(3):96-104.

2. Sadeghi H, Azizzadeh Foruzi M, Haghdoost AA, Mohammad Alizade S. Effect of implementing continuous care model on sleep quality of hemodialysis patients. Iranian Journal of Critical Care Nursing 2010; 3(1):56.

3. Potter P, Perry A, Stockert P, Hall A. Essentials for nursing practice. 8th ed. United States America: Elsevier Health Sciences; 2014.

4. Akbari V, Hajian A, Mirhashemi MS. Evaluating of sleep quality in shift-work nurses, Iran. J Sleep Disored Ther 2016; 5:225. doi:10.4172/2167-0277.1000225.

5. Asai T, Kaneita Y, Uchiyama M, Takemura Sh, Asai S, Yokoyama E, et al. Epidemiological study of the relationship between sleep disturbances and somatic and psychological complaints among the Japanese general population. Sleep Biol Rhythms 2006; 4(1):55-62.

6. Hojati H, Jalalmanesh Sh, Fesharaki M. Sleeplessness effect on the general health of hospitals nightshift nurses in Gorgan, Iran. 
Journal of Gorgan University of Medical Sciences 2009; 11(3):70-5.

7. Surani S, Hesselbacher S, Guntupalli B, Surani S, Subramanian Sh. Sleep quality and vigilance differ among inpatient nurses based on the unit setting and shift worked. J Patient Saf 2015; 11(4):215-20.

8. Feleke SA, Mulatu MA, Yesmaw YS. Medication administration error: magnitude and associated factors among nurses in Ethiopia. BMC Nurs 2015; 14(1):53.

9. Clendon J, Gibbons V. 12h shifts and rates of error among nurses: A systematic review. Int J Nurs Stud 2015; 52(7):1231-42.

10. Salehi K, Alhani F, Sadegh-Niat K, Mahmoudifar Y, Rouhi N. Quality of sleep and related factors among imam khomeini hospital staff nurses. Iran Journal of Nursing 2010; 23(63):18-25.

11. Arimura M, Imai M, Okawa M, Fujimura T, Yamada N. Sleep, mental health status, and medical errors among hospital nurses in Japan. Ind Health 2010; 48(6):811-7.

12. Johnson AL, Jung L, Song Y, Brown KC, Weaver MT, Richards KC. Sleep deprivation and error in nurses who work the night shift. J Nurs Adm 2014; 44(1):17-22.

13. Ghaljaei F, Naderifar $M$, Ghaljeh $M$. Comparison of general health status and sleep quality between nurses with fixed working shifts and nurses with rotating working shifts. Zahedan Journal of Research in Medical Sciences 2011; 13(1):47-50.

14. Soleimany M, Masoodi R, Sadeghi T, Bahrami N, Ghorban M, Hassanpoor A. General health and its association with sleep quality in two groups of nurses with and without shift working in educational centers of Iran University of Medical Sciences. Journal of Shahrekord University of Medical Sciences 2008; 10(3):70-5

15. Jafari Roodbandi A, Choobineh A, Daneshvar S. Relationship between circadian rhythm amplitude and stability with sleep quality and sleepiness among shift nurses and health care workers. Int J Occup Saf Ergon 2015; 21(3):312-7.

16. Vitale SA. Varrone-Ganesh J, Vu M. Nurses working the night shift: Impact on home, family and social life. J Nurs Educ Pract 2015; 5(10):70-8.

17. Lin SH, Liao WC, Chen MY, Fan JY. The impact of shift work on nurses' job stress, sleep quality and self-perceived health status. J Nurs Manag 2014; 22(5):604-12.

18. Palhares Vde, Corrente JE, Matsubara BB. Association between sleep quality and quality of life in nursing professionals working rotating shifts. Rev Saude Publica 2014; 48(4):594-601.

19. Weaver AL, Stutzman SE, Supnet C, Olson DM. Sleep quality, but not quantity, is associated with self-perceived minor error rates among emergency department nurses. Int Emerg Nurs 2016; 25:48-52.

20. Komada Y, Asaoka S, Abe T, Inoue Y. Short sleep duration, sleep disorders, and traffic accidents. IATSS Research 2013; 37(1):1-7.

21. Lowson E, Middleton B, Arber S, Skene DJ. Effects of night work on sleep, cortisol and mood of female nurses, their husbands and children. Sleep Biol Rhythms 2013; 11(1):713.

22. Fritschi L, Erren TC, Glass DC, Girschik J, Thomson AK, Saunders C, et al. The association between different night shiftwork factors and breast cancer: a case-control study. Br J Cancer 2013; 109(9):2472-80.

23. Buysse DJ, Reynolds CF 3rd, Monk TH, Berman SR, Kupfer DJ. The pittsburgh sleep quality index: a new instrument for psychiatric practice and research. Psychiatry Res 1989; 28(2):193-213.

24. Spira AP, Beaudreau SA, Stone KL, Kezirian EJ, Lui LY, Redline S, et al. Reliability and validity of the pittsburgh sleep quality index and the epworth sleepiness scale in older men. J Gerontol A Biol Sci Med Sci 2012; 67A(4):433-9.

25. Bagheri H, Shahabi Z, Ebrahimi H, Alaeenejad F. The association between quality of sleep and health-related quality of life in nurses. Hayat 2007; 12(4):13-20.

26. Morimoto H, Tanaka H, Ohkubo R, Mimura M, Ooe N, Ichikawa A, et al. Self-help therapy for sleep problems in hospital nurses in Japan: a controlled pilot study. Sleep Biol Rhythms 2016; 14:177-85.

27. Lin PC, Chen CH, Pan SM, Pan CH, Chen CJ, Chen YM, et al. Atypical work schedules are associated with poor sleep quality and mental health in Taiwan female nurses. Int Arch Occup Environ Health 2012; 85(8):877-84.

28. Rahimpoor F, Saeedi F, Fazli A, Mohammadi $\mathrm{S}$. The relationship of sleep quality and general health in shift working nurses. Occupational Medicine Quarterly Journal 2013; 4(4):8-13.

29. Moradi S, Farahnaki Z, Akbarzadeh A, Gharagozlou F, Pournajaf A, Abbasi AM, et al. Relationship between shift work and job satisfaction among nurses: a cross-sectional study. International Journal of Hospital Research 2014; 3(2):63-8.

30. Kim JY, Chae CH, Kim YO, Son JS, Kim JH, $\mathrm{Kim} \mathrm{CW}$, et al. The relationship between 
quality of sleep and night shift rotation interval. Ann Occup Environ Med 2015; 27:31.

31. Karagozoglu S. Bingöl N. Sleep quality and job satisfaction of Turkish nurses. Nurs Outlook 2008; 56(6):298-307. e3.

32. Rogers AE. The effects of fatigue and sleepiness on nurse performance and patient safety. In: Hughes RG, editor. Source patient safety and quality: an evidence-based handbook for nurses. Rockville, Maryland: Agency for Healthcare Research and Quality (US); 2008. Chapter 40.

33. Parkes KR. Age and work environment characteristics in relation to sleep: Additive, interactive and curvilinear effects. Appl Ergon 2016; 54:41-50
34. Del Brutto OH, Mera RM, Sedler MJ, Zambrano M, Nieves JL, Cagino K, et al. The effect of age in the association between frailty and poor sleep quality: a population-based study in community-dwellers (the atahualpa project). J Am Med Dir Assoc 2016; 17(3):269-71.

35. Kageyama $\mathrm{T}$, Nishikido $\mathrm{N}$, Kobayashi $\mathrm{T}$, Kawagoe H. Estimated sleep debt and work stress in Japanese white-collar workers. Psychiatry Clin Neurosci 2001; 55(3):217-9.

36. Takeyama H, Itani T, Tachi N, Sakamura O, Murata $\mathrm{K}$, Inoue $\mathrm{T}$, et al. Effects of shift schedules on fatigue and physiological functions among firefighters during night duty. Ergonomics 2005; 48(1):1-11. 